\title{
Safe medical staffing: a move towards modelling the medical workforce establishment in practice
}

\author{
Authors: Rhiannon Hughes, ${ }^{*}$ Benjamin Pope and Kiaran Flanagan
}

\section{Introduction}

In 2018, for the first time, the Royal College of Physicians (RCP) published guidance on safe medical staffing requirements. ${ }^{1}$ This included a benchmark of the number of hours required to provide care to medical inpatients from different tiers of clinicians. This led us, within North Bristol Trust's (NBT) medical division to ask the question - do we have enough doctors?

Of note, in calculating the benchmark, the RCP guidance does not account for additional activities undertaken by Tier 1 clinicians, for example clinic requirements, and Tier 2 clinicians allocated to the ward, were estimated to be available $70 \%$ of the time, which at NBT was felt to be an underestimate.

As chief registrar, and collaborating with an internal analyst, we undertook a workforce modelling exercise, fundamentally based on the RCP guidance, but with refinements to account for our obligation to protect time required for training as per GMC recommendations. ${ }^{2}$

\section{Materials and methods}

Analysis of the on-call rosters identified hours rostered for ward work. In agreement with RCP guidance, predictable absences were calculated, plus an allowance for sickness ( 5 days per person).

Information was collated from the postgraduate education department regarding teaching hours and clinic requirements, and specialty registrars were surveyed regarding time necessary for specific training requirements. This was corroborated using to JRCPTB decision aids. ${ }^{3}$

Medical staffing provided information on posts and vacancies.

This data was then compared to the RCP guidance of recommended hours required to provide inpatient care, according to our bed base and patterns of working.

\section{Results and discussion}

Overall from the current posts the model calculated that across the Tier 1 workforce there is an additional 517 hours per week and in Tier 2 there is a deficit of 343 hours from the minimum RCP benchmark. Excluding vacant posts results in Tier 1 having an additional 110 hours, and a Tier 2 deficit of 366 hours (See Table 1).

While accounting for additional training requirements, according to this model, there are sufficient posts in Tier 1 to meet the RCP benchmark for ward staffing in hours. However, at Tier 2 the numbers of posts do not meet the benchmark. If the model had used the more conservative figure provided by the RCP for Tier 2 staff unavailability, rather than the figure estimated from surveying current registrars, it remains under-established, at - 200 hours per week. There is likely to be compensation from Tier 1 staff (eg CT2s), and from Tier 3 cover, to support Tier 2 workload.

Table 1: Tier 1 and Tier 2 variance from benchmark time required for safe ward staffing

\begin{tabular}{|c|c|c|c|c|c|c|}
\hline Tier & $\begin{array}{l}\text { Benchmark: } \\
\text { time required for } \\
\text { RCP safe ward } \\
\text { staffing (hrs) }\end{array}$ & $\begin{array}{l}\text { Total rostered } \\
\text { hours for } \\
\text { ward work } \\
\text { (hrs) }\end{array}$ & $\begin{array}{l}\text { Unavailable time for } \\
\text { ward work: due to } \\
\text { leave and training } \\
\text { requirements (hrs) }\end{array}$ & $\begin{array}{l}\text { 'Real' time } \\
\text { remaining } \\
\text { for ward } \\
\text { work (hrs) }\end{array}$ & $\begin{array}{l}\text { Variance } \\
\text { from } \\
\text { benchmark } \\
\text { (hrs) }\end{array}$ & $\begin{array}{l}\text { Variance } \\
\text { from } \\
\text { benchmark } \\
(\%)\end{array}$ \\
\hline 1 & 1,107 & $2,238.3$ & 614.2 & $1,624.1$ & 517 & 46.7 \\
\hline 2 & 540.2 & 533.9 & 336.5 & 197.4 & -342.8 & -63.5 \\
\hline 1 (excluding unfilled posts) & 1107 & $1,769.6$ & 533 & $1,216.5$ & 109.47 & 9.9 \\
\hline 2 (excluding unfilled posts) & 540.2 & 486.4 & 311.9 & 174.47 & -365.71 & -67.7 \\
\hline
\end{tabular}

Authors: North Bristol NHS Trust

${ }^{*} \mathrm{RCP}$ chief registrar 


\section{Conclusion}

This work enhances the understanding of the medical workforce establishment, as the model gives a more accurate estimation of our requirements. Prior to undertaking this exercise we had hypothesised that we needed to create additional posts in Tier 1 workforce. However, this work has changed our focus within the division, onto strategies for expansion of Tier 2 posts while improving recruitment to existing posts at Tier 1.

Future work is required to adapt the model to evaluate workforce at the specialty level and evaluate out-ofhours cover.

\section{References}

1 General Medical Council. National training surveys 2018: Initial findings report. London: GMC, 2018. www.gmc-uk.org/-/media/ documents/dc11391-nts-2018-initial-findings-report_pdf75268532.pdf [Accessed January 2019].

2 Joint Royal College of Physicians Training Board. ARCP decision aids. London: JRCPTB. www.jrcptb.org.uk/training-certification/ arcp-decision-aids.

3 Royal College of Physicians. Guidance on safe medical staffing Report of a working party. London: RCP, 2018. 